\title{
ANALYSIS OF USING DIGITAL LEARNING MATERIALS IN ENGINEERING LABORATORY COURSES
}

\author{
TSVETELINA GEORGIEVA ${ }^{1 *}$, TZVETELIN GUEORGUIEV ${ }^{1}$, \\ SEHER KADIROVA ${ }^{1}$, BORIS EVSTATIEV ${ }^{1}$, NIKOLAY MIHAILOV ${ }^{1}$ \\ ${ }^{1}$ University of Ruse “Angel Kanchev", Studentska 8, Ruse, 7000, Bulgaria
}

\begin{abstract}
The paper presents an analysis of the use of digital learning materials in engineering laboratory courses. Interviews have been conducted with lecturers from several engineering faculties of the University of Ruse 'Angel Kanchev', such as: the Faculty of Electrical Engineering, Electronics and Automation, the Faculty of Transport, and the Faculty of Mechanical and Manufacturing Engineering. The aim of the interviews is to investigate the capacity and understanding of the lecturers in respect to using digital learning materials in laboratory courses. The obtained results demonstrate that digital learning materials are perceived as a useful tool to achieve better engagement of students in the educational processes. This would require continuous additional efforts by the teaching staff and permanent updating of their specific and digital competences.
\end{abstract}

Keywords: digital learning materials, engineering education, interviews

\section{INTRODUCTION}

The need to improve the quality of engineering education to meet the requirements of industry and the expectations of students is well established. In this context, there is a strong case for exploiting the opportunities made available by e-learning to enhance the learning experience of engineering students. Despite the potential benefits, many students and teaching staff would argue that developing or accessing suitable engineering elearning resources can be challenging.

Engineering is a practicing profession devoted to harnessing and modifying the three fundamental resources that humankind has available for the creation of all technology: energy, materials, and information. The overall goal of education is to prepare students to practice engineering and, in particular, to deal with the forces and materials of nature. Thus, from the earliest days of engineering education, instructional laboratories have been an essential part of undergraduate and, in some cases, graduate programs. Indeed, prior to the emphasis on engineering science, it could be said that most engineering instruction took place in the laboratory.

In Bulgaria, e-learning is still in the beginning of its development, and the existing courses are very often not completely finished (missing lectures, exercises, tests and other major components). Some universities have not yet published on-line courses, but following modern trends in higher education they will have to fill out their virtual libraries according to European and global expectations in this area. Modern engineering education requires laboratory training exercises, necessary for acquiring a number of minimal practical knowledge. For this reason distance learning is impractical or partially applicable in engineering specialties, therefore alternative methods for its realization should be sought.

\footnotetext{
"Corresponding author, email: cgeorgieva@uni-ruse.bg
}

(C) 2018 Alma Mater Publishing House 
With the development of communication technology, digital learning becomes a real alternative to traditional education, as a result of several prerequisites [1]:

- The trainees themselves set their pace and schedule of training according to their free time and opportunities;

- Learning materials can be relatively easy and cheap to be updated as they are mainly in electronic form;

- Learning materials can be accessed by both personal computers and laptops, as well as mobile devices.

Recent studies have revealed a worldwide declining interest in the enrolment of students in educational degrees related to technical disciplines (STEM - Science, Technology, Engineering, and Mathematics). Nowadays, the economy needs more graduate engineers for both engineering and non-engineering jobs, therefore most industrialized economies in Europe are expected to find a long-term sustainable solution [2].

Today simulators are used to deliver training for all kinds of activities, from piloting sophisticated aircraft or ships to operating nuclear power plants or complex chemical processing facilities. Simulation software programs that accurately emulate many technical and physical processes are available. These software programs play an important role in engineering education.

The aim of this paper is to present the analysis of a study regarding the use of digital learning materials in engineering laboratory courses at the University of Ruse 'Angel Kanchev', and to investigate the capacity and understanding of the use of digital learning materials by the lecturers from the engineering faculties. The analysis is based on interviews with lecturers from the main engineering faculties.

\section{EXPERIMENTAL SETUP}

\subsection{Laboratory and practical work in the engineering education}

Laboratory and practical work are characteristic features of bachelor and master degree education in any engineering program [3]. The role of practical work in engineering education is [4]:

- To motivate students and to stimulate their interest in the subject of the course;

- To help the students deepen their understanding by relating theory to practice;

- To provide opportunities for the students to work together on different real engineering problems, to analyze and solve them;

- To develop skills that will enable the students to work effectively and professionally in a real engineering workplace.

Laboratory and practical works also have some disadvantages. In some cases they are expensive and require specialized equipment, thus requiring time and laboratory space to manage the equipment. These disadvantages could be reduced by using digital learning materials.

Digital teaching in higher education for engineering laboratories and capacity analysis of higher education teachers are some of the main tasks of the Erasmus project ESCOLA - Engineering student-centered learning approaches.

\subsection{Project escola - engineering student-centered learning approaches}

The aim of the project ESCOLA is to develop a new supportive learning environment for engineering classes that will help students understand and evaluate engineering applications in practice. This learning environment will be introduced to teachers who use engineering laboratories for their courses, so that they can efficiently improve the quality of the learning experience for students with the help of visual and interactive tools.

The main target group of ESCOLA are higher education (HE) teachers who include engineering laboratory training into their courses. It can be said that HE teachers are open to innovations, are highly knowledgeable in their research area, and thus, they might not resist to progress and change in the methods of teaching. However, a large proportion of them lack the information and communication technologies (ICT) skills required to access and effectively use digital interactive resources and/or to envisage how to include such technology into their traditional teaching strategies.

Intellectual output 1 (IO1) of the project is "Digital Teaching in Higher Education for Engineering Laboratories and Pedagogic Assessment of Available Tools", and intellectual output 2 (IO2) is "Capacity Analysis of Higher Education Teachers". 
The description of IO1 includes searching and evaluating current ICT tools and techniques that are used for teaching in engineering laboratory practices in HE. Next, they are researched and categorized by compromising mobile, online and digital resources suitable to be used in engineering laboratories teaching/learning environment. Research is completed and a report is prepared in order to:

- Show existing range of digital resources for teaching and learning activities at engineering laboratories;

- Categorize these digital resources by the content of engineering laboratory courses in HE;

- Select the most promising tools regarding their pedagogical assets (selection of at least 10 ICT tools).

IO2 includes the methodology of capacity analysis, evaluation of current ICT skills and knowledge of HE teachers, as well as their needs for laboratory courses, such as: types of supplementary tools and materials for laboratory teaching. This intellectual output is aimed at identifying the ICT knowledge and capacity of HE teachers to use digital learning materials in their engineering laboratory courses in order to improve the skills and knowledge of students both in terms of relevant course outputs, and in terms of ICT abilities.

\subsection{Interview of higher education lecturers}

The interview of the lecturers aims to investigate the capacity and understanding of the lecturers at the engineering faculties to use digital learning materials in laboratory courses. The interview consists of 4 questions. Participation in this study and answering each question are voluntary for the lecturers. This interview takes approximately 10 to 15 minutes.

The interview questions are:

1- How do you lecture your laboratory courses?

a. Do you use digital learning materials in your laboratory courses?

b. How do you find your digital learning materials in laboratory courses?

c. What are your views on the use of digital learning materials in laboratory courses?

2- Are the digital learning materials that you are currently using in your laboratory courses sufficient? Are they fit for purpose?

a. What if there are shortcomings?

b. Are there any other types of digital tools that you could help improve your teaching?

3- In your opinion, what functions should digital learning materials have for best use in laboratory courses?

a. Cognitive

b. Technical

4- What effect does the inclusion of digital learning materials in your laboratory lessons have on your students'...

a. Motivation?

b. Academic success?

\section{RESULTS AND DISCUSSION}

The University of Ruse 'Angel Kanchev' has conducted 5 interviews with higher education lecturers from the following faculties: the Faculty of Electrical Engineering, Electronics and Automation, the Faculty of Transport, and the Faculty of Mechanical and Manufacturing Engineering. Figure 1 presents the strata of the sampled lecturers by their age and experience.

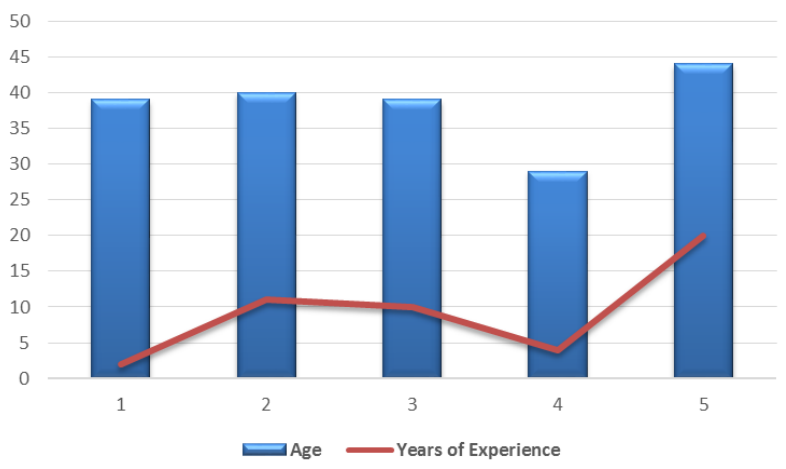

Fig. 1. Interviewed lecturers by age and years of teaching experience. 
The average age of the interviewed lecturers is 38.2 years, and their average teaching experience is 9.4 years. The age of the lecturers suggests that they are familiar with digital learning materials (DLM) and tools. At the same time their teaching experience allows them to have a realistic view of the teaching process and to be aware of both professional software, and the current needs and expectations of 'Generation Z' students.

Upon the completion of the interviews, the answers to the four main questions listed above have been tabulated and analyzed. An overview of the obtained results is presented below.

The answers to the first question are given by providing insight on three sub-questions:

a. Do you use DLM in your laboratory courses?

All lecturers give positive answers to this question. There are some nuances in the details such as: using DLM mainly in the lectures, some laboratory exercises having direct requirements for the use of DLM, etc.

b. How do you find your DLM in laboratory courses?

The internet is the 'number one' source of DLM. It is followed by the virtual library of the university, the municipal library of Ruse, proceedings and videos from conferences, online training centers of specialized companies, etc. A very positive finding of the interviews is that $40 \%$ of the lecturers prepare DLM themselves. This speaks of their own motivation, devotion and competence.

c. What are your views on the use of DLM in laboratory courses?

The answers to this question range from 'very useful' to 'a nice addition to the classical way of teaching'. Nevertheless, all lecturers declare that they realize the importance of DLM for the students' acceptance and understanding.

The second question is also subdivided into two specific questions:

a. What if there are shortcomings?

Two of the five lecturers see no shortcomings in the DLM that they use currently. The fact that 'the fastchanging technologies make the search of DLM a permanent task' is perceived as a shortcoming by one of the interviewed lecturers. At the same time, a colleague of his sees the problem in the lecturers themselves who 'think that we are up-to-date'.

b. Are there any other types of digital tools that you could help improve your teaching?

The variety of additional opportunities for improving the DLM used for teaching include:

- Virtual labs;

- Simulation tools and digital learning platforms;

- Broader access to digital technical articles and databases;

- Use of videos, movies, presentations, especially when systems are hard to access when installed;

- Increasing the number of practical exercises, extended work with modern software and equipment.

The third question is related to the cognitive and technical features of DLM:

a. Cognitive - Figure 2 presents a mind map of the answers given by the interviewed lecturers.

b. Technical - a summary of these answers is given below:

- Presenting the actual operation of systems;

- Providing simulation capabilities which are not practical in real working conditions;

- Capable of presenting phenomena or processes that are invisible to the human eye (for example, magnetic field, current flow in AC/DC circuits);

- Comparisons between real practical results against the simulation results;

- Comparisons of technical characteristics and parameters of different devices and systems;

- Quick and full understanding of concepts, improving instructional techniques, leveraging lecturers' use of time, facilitating the sharing of knowledge, etc. 


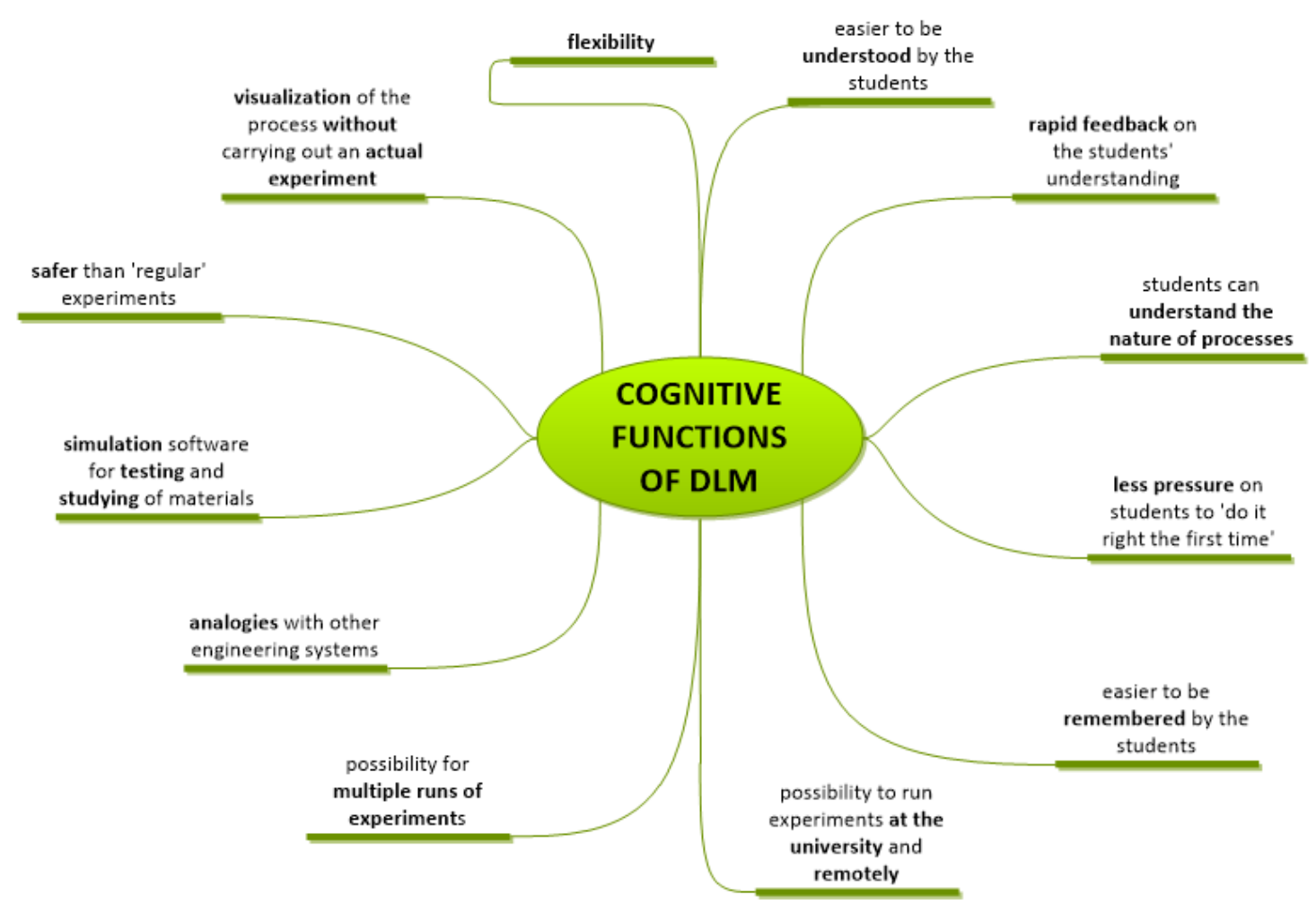

Fig. 2. Mind map of the ideas for the cognitive functions of digital learning materials.

The fourth question deals with the effect of the use DLM. Two aspects are considered:

a. Motivation

All lecturers agree that the inclusion of DLM will improve the motivation of the students. According to the lecturers, some of the possible ways to achieve higher motivation are:

- More contemporary technologies;

- Impressive look of the DLM;

- Presenting the visualization / simulation first, and then carrying out the actual laboratory exercise;

- Students making videos of the actual laboratory experiments, sharing and commenting on them with their lecturers and colleagues;

- Team work and individual (independent) work,

- Helping students without prior knowledge in the subject area;

- Quick feedback.

b. Academic success

$80 \%$ of the interviewed lecturers believe that the improved academic success of the students can be achieved by the inclusion of DLM. They see the academic success as correlated with the motivation of the students. In one of the cases the lecturer says that 'students are even motivated to engage in out-of-class activities at the laboratory'. This is a potential consequence of presenting the theory and practice of the respective science as DLM which are a 'smooth transition from entertainment to learning'. In addition, DLM 'are closer to the way of life of contemporary students' and 'help the students prepare better'.

\section{CONCLUSIONS}

The main conclusion is that DLM are perceived as a useful tool to achieve better engagement of students in the educational processes. This would require continuous additional efforts by the teaching staff and permanent updating of their specific and digital competences. From a managerial perspective, additional funds and infrastructure will have to be made available. Application of DLM in engineering laboratory education will improve their realization, reduce the need for specialized equipment, and save time to manage the equipment. 


\section{ACKNOWLEDGEMENT}

This work is supported by the Erasmus+ Program of the European Union ESCOLA - Engineering StudentCentered Learning Approaches (No. 2017-1-TR01-KA203-045955).

\section{REFERENCES}

[1] Doncheva, J., Ivanova, E., Contemporary challenges and expectations of inclusive education in the Republic of Bulgaria. IN: VI International Scientific Conference 'Contemporary Education - Condition, Challenges and Perspectives', 'Goce Delchev' University - Shtip, Macedonia, Faculty of educational sciences, 2018, p. 152-160.

[2] Katzis, K., Dimopoulos, C., Meletiou-Mavrotheris, M., Lasica, I.E., Engineering Attractiveness in the European Educational Environment: Can Distance Education Approaches Make a Difference?, Education Science, vol. 8, no. 16, 2018, p. 1-21.

[3] Feisel, L., Rosa, A., The role of the laboratory in undergraduate engineering education, Journal of Engineering Education, 2005, p. 121-130.

[4] Nikolic, S., Suesse, T., Goldfinch, T., McCarthy, T., Relationship between learning in the engineering laboratory and student evaluations, Proceedings of the Australasian Association for Engineering Education Annual Conference, 2015, p. 1-9. 